\title{
Comparative Effect on Skin Bacterial Counts of Surgical Skin Preparations, After Preoperative Showering with Anionic and Cationic Soaps
}

\author{
Andrew Kemp ${ }^{1 *}$, Vanessa Hodgkinson ${ }^{2}$ and A Bugg ${ }^{3}$ \\ ${ }^{1}$ University of Lincoln Rope Walk, UK \\ ${ }^{2}$ Nottingham University Hospitals, UK \\ ${ }^{3}$ Leicester University, UK \\ *Corresponding author: Andrew Kemp, Reader in Biology, Sparkhouse Building, University of Lincoln Rope Walk, Lincoln, LN67DQ, \\ UK \\ To Cite This Article: Andrew Kemp. Comparative Effect on Skin Bacterial Counts of Surgical Skin Preparations, After Preoperative Showering with \\ Anionic and Cationic Soaps. Am J Biomed Sci \& Res. 2019 - 6(1). AJBSR.MS.ID.000983. DOI: 10.34297/AJBSR.2019.06.000983.
}

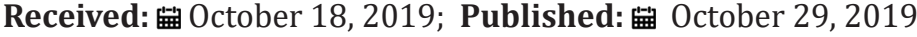

\begin{abstract}
The authors investigated the effect over time, that preoperative showering with anionic and cationic soaps has on the effectiveness of the surgical skin preparation (skin disinfectant) used in the operating room. It has been long known that the ionic charge of detergents and soaps, can have a detrimental effect to the efficacy of skin disinfectants used thereafter [1]. The authors randomized 100 patients into test groups, using anionic and cationic soaps followed by common surgical skin preparations. Bacterial burden on the skin was then measured at 4 time points up to and including 4 hours after application. The results showed that there was a decrease in efficacy of Chlorhexidine Gluconate (CHG) $0.5 \%$ and $2 \%$, at each time point when an anionic soap was used as compared to a Cationic soap. The same effect was not observed in other common surgical skin preparations, whose efficacy remain largely unchanged.
\end{abstract}

\section{Background}

Surgical site infections (SSIs) occur in approximately 2\%-5\% of patients who undergo clean extra abdominal surgeries, such as thoracic and orthopedic surgery, and in up to $20 \%$ of patients who undergo "open" intra-abdominal surgery interventions [2,3]. They can lead to increased morbidity and mortality and are associated with prolonged hospital stay and greater hospital costs [2-5]. The significance of skin bacteria around surgical wounds and their direct/ indirect effect as a cause of Surgical site infections (SSI's) have therefore been well documented and recommendations made by agencies such as the United States Centre for Disease Control (USCDC) and the UK National Institute for Health and Care Excellence (NICE) [6,7].

In 2017 the USCDC published the long-awaited update to its 1999, guidance on prevention of surgical site infections $[3,6]$. There were several new recommendations, and a few surprises, not least in the number of primary references used for the new document. The number of primary references decreased from 497 in 1999 (with 20 selected readings), to just 170 in 2017. Of the 5759 titles and abstracts screened, 896 underwent full-text review, leaving just 170 studies to take extracts and conclusions from. The reasoning given was that the academic level required for primary references had been raised, meaning numerous papers felt to be relevant in 1999, were no longer of enough academic quality, to meet the standards required for a primary reference in 2017. An essential procedure in preventing SSI's, is the pre-operative cleaning and disinfection of the skin $[2,3,6]$. Procedures that came under significant scrutiny in both the 1999 and 2017 USCDC documents, were the need for patients to pre-operative shower and, the preparation of the skin immediately prior to surgery in the operating room. The first recommendation listed in the guidance, is the preoperative showering requirement. According to the USCDC's 2017 recommendations, the preparation of skin prior to surgery is now considered to be a single issue with a 2-stage procedure. Stage 1. Is to ensure that the patient preoperatively showers, and stage 2 is to use a skin disinfectant to clear the skin edges and surrounding area of bacterial load just prior to incision. Although the USCDC do recommend the skin disinfectant chemicals to be used, there is no mention of the type of soap that should be used for the preoperative shower. 
As one of the skin disinfectants recommended is CHG in $70 \%$ alcohol, and it is well known that this is affected by the ionic charge from soaps [8-11], it was felt that the effect of the choice of soap in relation to the outcome of the recommended skin disinfectants, plus other commonly used skin disinfectants that were not mentioned in the USCDC documents, should be investigated. CHG came into medical use in the 1950s. It is on the World Health Organization's List of Essential Medicines, the most effective and safe medicines needed in a health system. There is tentative evidence that it is more effective than povidone-iodine. CHG is active against Gram-positive and Gram-negative organisms, facultative anaerobes, aerobes, and yeasts. It is particularly effective against Gram-positive bacteria. Significantly higher concentrations are required for Gram-negative bacteria and fungi. There are now numerous strains of dangerous pathogens resistant to CHG [12]. Unfortunately, some of these pathogens are also resistant to Colistin (last resort antibiotic) [12]. CHG is deactivated by forming insoluble salts with anionic compounds, including the anionic surfactants commonly used as detergents or soaps. The potential for residual anionic soaps to be left on the skin after preoperative showering was not mentioned in any of the guidance documents.

The authors felt the surgical community needed to understand if the potential combination choice would have any effect on skin CFU counts, and species, therefore potentially on surgical infection rates. In 2009, the WHO produced their guidance on hand hygiene in healthcare [8]. One of the cautions in this document (section 11.4) states that; "because chlorhexidine is a cationic molecule, its activity can be reduced by natural soaps, various inorganic anions, non-ionic surfactants, and hand creams containing anionic emulsifying agents". Additionally, in June 2016, in a paper that reviewed all the available evidence of measured interactions between CHG and anionic chemistries [1], the authors gave the following recommendations; "clinicians should carefully consider the nature of topical agents used if CHG is concurrently applied. Increased awareness of CHG incompatibility may result in better antibacterial activity thus ensuring optimal patient management". If these variables are not isolated in studies, the "Evidence" in reference to patient outcome infection control studies, should therefore be considered at best weak [13].

At physiologic $\mathrm{pH}$, chlorhexidine salts dissociate and release the positively charged chlorhexidine cation. The bactericidal effect is a result of the binding of this cationic molecule to negatively charged bacterial cell walls. At low concentrations of chlorhexidine, this results in a bacteriostatic effect; at high concentrations, membrane disruption results in cell death. Although the clinical effectiveness of pre surgical antiseptic showers have been reported in 3 Randomized Controlled Trials (RCTs) and 4 cohort studies $[10,11]$, no account was taken in respect to the ionic status of the shower gel or soaps used in these studies. The clinical effectiveness of antiseptic preparation versus non medicated soap and alcohol or saline was reported in 2 RCTs published in 2001 and $2005[14,15]$.
In July 2018, the authors of this study, published the results of a study on the effects over time, of three commonly used surgical skin preparations including CHG [13] on skin CFU counts for patients undergoing abdominal surgery. One of the failings of the paper, was that it did not identify the soap type (anionic or cationic) used for the preoperative showering. Although the patients were randomized into each group by surgical skin prep. All patients were asked to confirm they had preoperatively showered. In order to ensure $100 \%$ compliance with the study protocol, all patients who did not confirm this were asked to shower in hospital prior to moving through to surgery. There was no data collection on type of soap used and therefore no data on the Ionic status of the soaps.

The study, therefore, did not control for any potential effect that different soap types used for preoperative showering, would have on bacterial skin counts when using the various surgical skin preps. At the time, the main body of available evidence from studies into post op infection rates in relation to surgical skin preparation, pointed towards $\mathrm{CHG}$ as being the most effective as compared to the other most commonly used surgical skin disinfectant, Povidone Iodine (PI) $[5,16,17]$. The earlier study therefore only compared two other commonly used skin disinfectants against CHG and not PI (see graph below) (Graph 1).

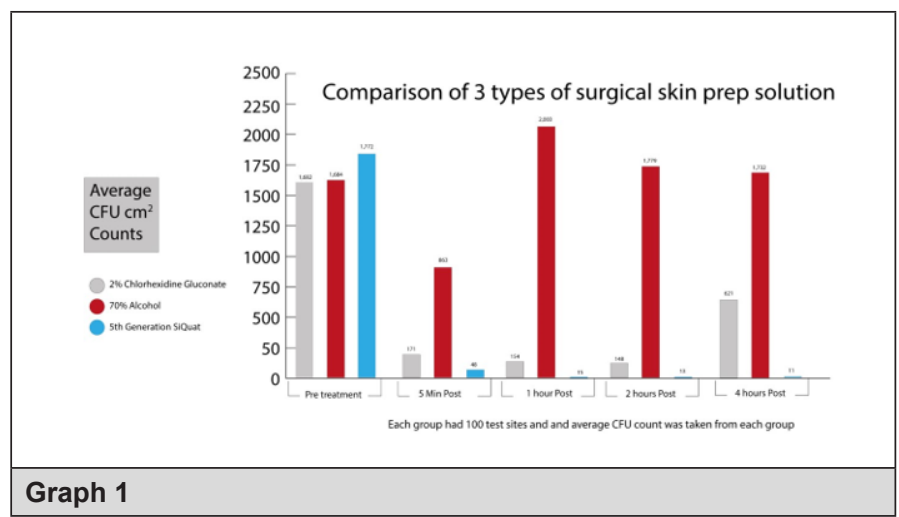

\section{Method}

As the authors could not find any reference to the type of soap used in any of the other comparative studies, the authors felt the need to include PI in this study. Abdominal surgical patients were the group chosen, and the commonly used area of the longitudinal midline incision of the abdomen as the area to sample. This type and area of incision has been used for many studies looking at levels of bacterial contamination [18-24]. In addition, the study protocols for this group were already approved. Time periods chosen for the testing were the same as in the first paper, as these were still felt to be the most relevant in the study group. These are, the period between "skin preparation" and "knife to skin" (approximately 5mins), 1 hour, 2 hours and 4 hours post application [24-26].

This study includes the use of CHG $2 \%$ in $70 \%$ alcohol, CHG $0.5 \%$ in $70 \%$ alcohol, PI $7.5 \%$ in $70 \%$ alcohol, a 5 th generation long acting Silane Quaternary compound (SiQuat) with low concentration of alcohol (aqueous solution) and a 70\% ethyl 
alcohol solution with no other active ingredient. 200 patients were randomized into each disinfectant group, and then randomized again into a liquid cationic soap group and a liquid anionic soap group, for preoperative showering. Therefore, each subgroup has 100 patients in it. All patients showered in hospital prior to surgery, to ensure they used the correct product. As the soaps and the skin disinfectants are easily identified by staff by color and smell, only the patients were blinded to the study groups. Again, as per the previous study, testing of skin bacterial CFU's was done using the Bacteria Specific Rapid Metabolic Assay (BSRMA) techniques. Although very reliable and accurate, these techniques were almost unknown in 2018, however they have been used in numerous published studies and are well described in a 2019 paper, that reviewed and compared the available bacterial test methods [2731]. Average CFU counts for each group were then compared, as an indication of any changes in efficacy of the chemical disinfectant after anionic and cationic soap were used.

In addition, samples were also cultured to determine if a change in bacterial species had occurred, as this had been seen in studies using high concentrations of alcohol [27,32,33]. A nonselective media, Nutrient Agar (NA) and Brain Heart Infusion
(BHI) agar, were used for both Total Aerobic Counts (TAC) and total anaerobic counts. Inoculated media were incubated at an appropriate temperature between $30-370 \mathrm{C}$ for a minimum of 24hours. Indicator species for contaminated/very contaminated samples were outlined as S. aureus/MRSA, S. epidermidis, VRE and Gram-ve bacilli.

All samples were taken from areas of abdominal skin $2 \mathrm{~cm} \times 1 \mathrm{~cm}$ along the midline running superior to inferior using a sterile technique. These areas were marked with a surgical skin marker to ensure that further samples were taken from the same areas. A sample from every area was taken prior to any skin prep being used and a surface count recorded using a BSRMA, technique, as well as a sample sent for culture. All areas were prepared for surgery using one of the chosen skin antimicrobial preparations. Due to color variations in the liquid preparations it was impossible to blind the study. A 2nd culture sample was taken at 4 hours post application.

\section{Results}

The graphs below show the average skin bacterial counts for the 2 concentrations of $\mathrm{CHG}$ when used with Anionic and Cationic soaps (Graph 2).

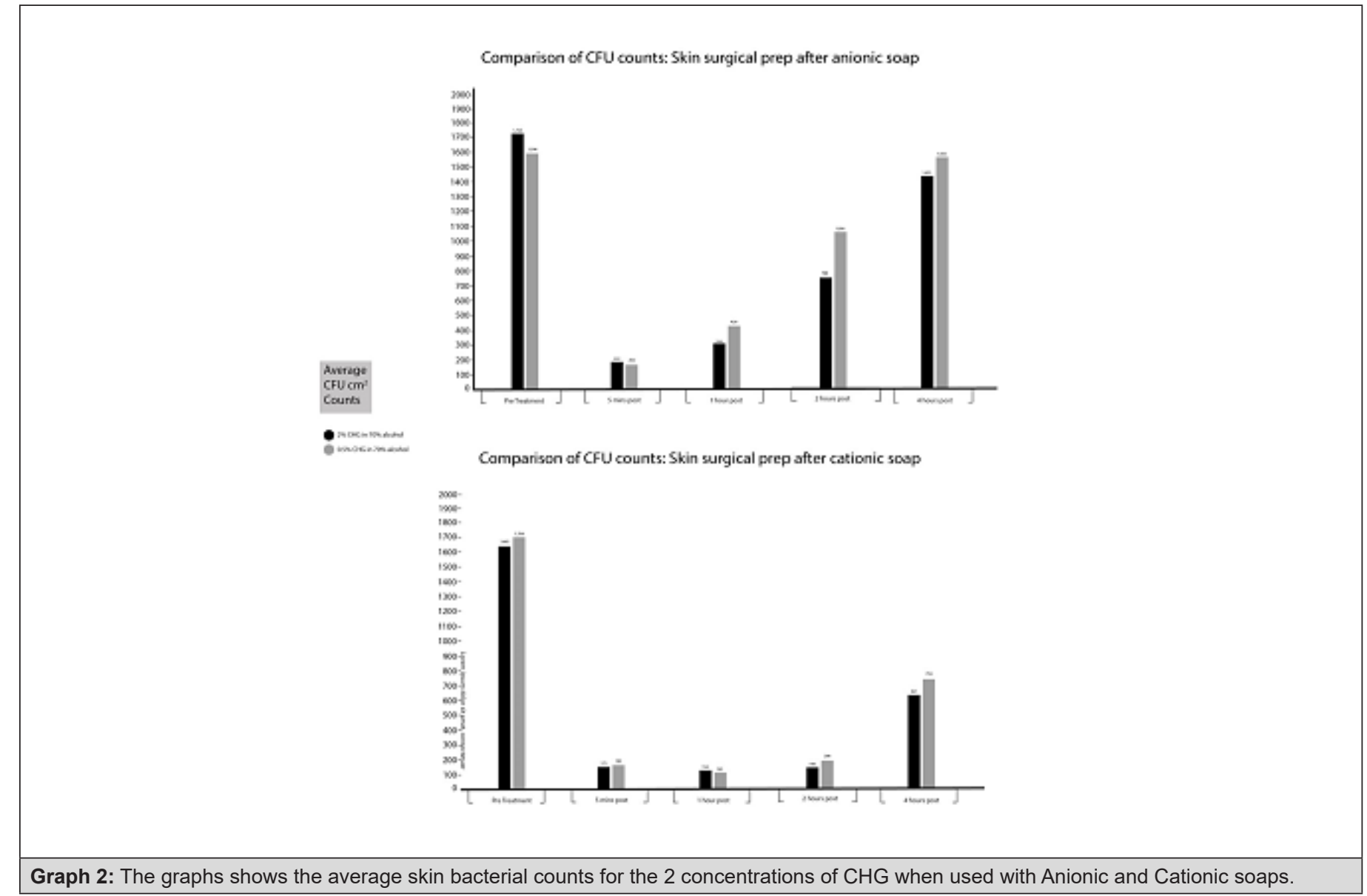

The following table shows the \% reduction in efficacy for both CHG groups when an anionic soap is used in comparison to a cationic soap (Table 1). When compared to other 3 other commercially available surgical skin preparations a different picture emerges.
The graphs below show the average skin bacterial counts for the 5 types of surgical skin prep when used with Anionic and Cationic soaps (Graph 3). 
Table 1: The following table shows the \% reduction in efficacy for both CHG groups when an anionic soap is used in comparison to a cationic soap.

\begin{tabular}{|c|c|c|c|}
\hline \multicolumn{1}{c}{} & \multicolumn{3}{c}{ CHG concentration } \\
\cline { 2 - 4 } & & $0.5 \%$ & $2 \%$ \\
\cline { 2 - 4 } Hrs post & 1 hour & $67 \%$ & $52 \%$ \\
\cline { 2 - 4 } application & 2 hours & $86 \%$ & $74 \%$ \\
\cline { 2 - 4 } & 4 hours & $52 \%$ & $57 \%$ \\
\cline { 2 - 4 } & & &
\end{tabular}

There appears to be only a small difference in bacterial counts for the PI and alcohol 70\% with bacterial counts peaking at 1-hour post application, and then reducing slightly over the next 3 hours. The 5th generation SiQuat group was not affected by the choice of ionic soap. The pattern of antimicrobial activity observed in previous papers remains essentially unchanged for all disinfecting chemistries. After a large initial reduction in bacterial counts at 5 mins post application, there is a continual increase in bio burden over the 4-hour period in all but the 5 th generation SiQuat group. There are, however, large differences in bacterial counts in both CHG groups, dependent on the ionic content of preoperative shower soap, from 1-hour post application. In the alcohol 70\% group, there was also a change in dominant species from S. Epidermidis to Gram-ve Bacilli, this change in species was not observed in any other group, all of which also contain alcohol.

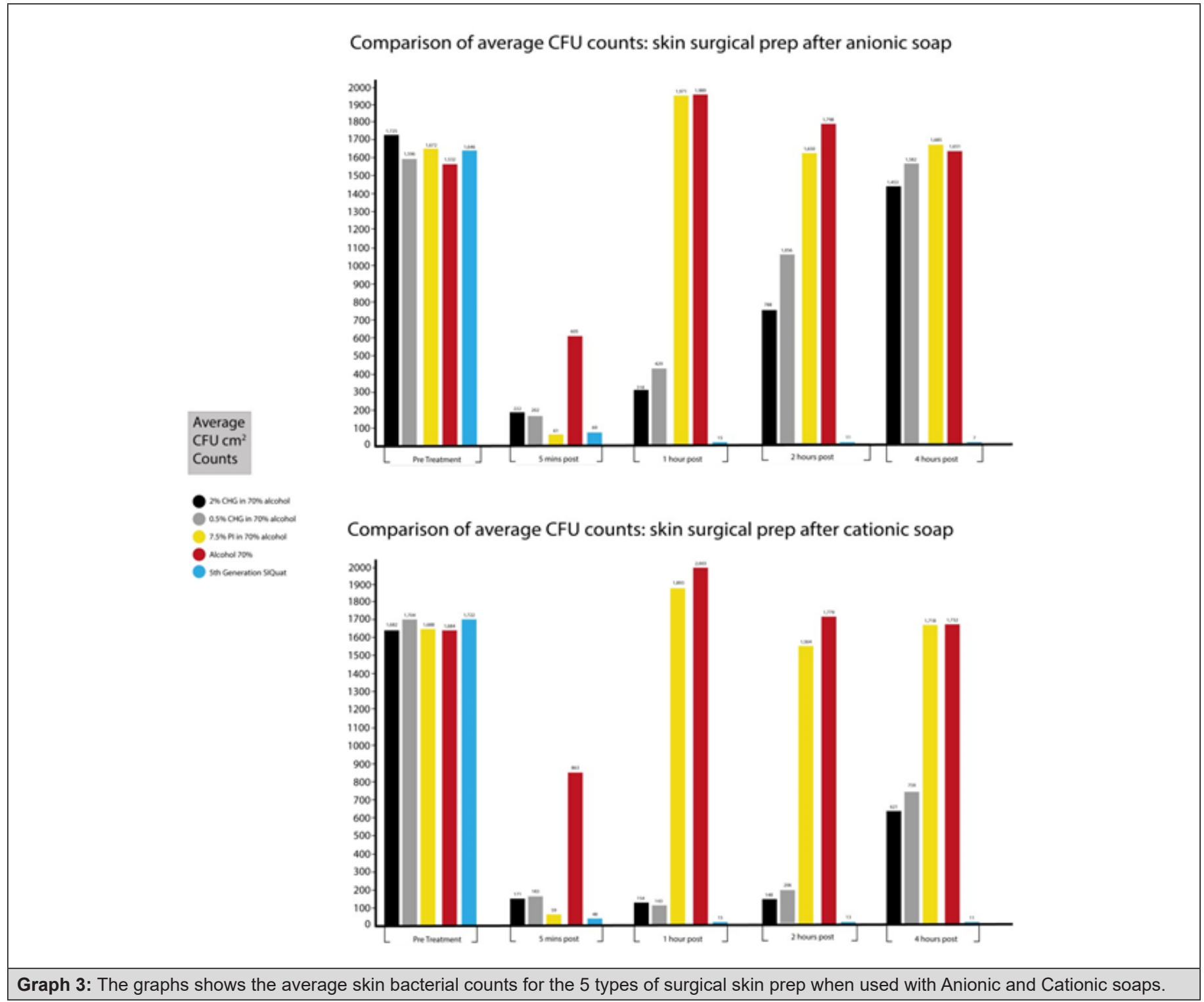

\section{Conclusions and Recommendations}

These results from this study, confirm the WHO caution for clinicians that states based on the cited papers [9-11], anionic soaps may reduce the efficacy of CHG on patients' skin is correct.
There is a clear reduction in antimicrobial efficacy seen over time when an anionic soap is used for preoperative showering. As in the 2018 study [13], the results showed that the long acting SiQuat not only killed more quickly than the $\mathrm{CHG}$, and other skin prep 
solutions tested, it continued to do so more effectively for 4 hours after application. Due to the species change from S. epidermidis to Gram-ve bacilli, and the overall poor CFU results over time, when using alcohol without a 2nd antimicrobial, the authors would not recommend this as a suitable preoperative skin disinfectant. As there was no opportunity to study the SSI outcomes of the patients, it is impossible to know what the significance of overall effect of the various antimicrobial solutions had on infection rates.

For the moment then, common sense would therefore dictate that, with no species change, the lower the skin counts, the lower the potential for SSI rate from skin bio burden. Selection of both the preoperative shower gel, and the skin disinfectant in combination would therefore seem extremely important. If CHG is the chosen surgical per operative skin disinfectant, patients should be advised to use a cationic soap for their pre-operative shower. Numerous highprofile organizations and people, including the UK Chief Medical Officer Dame Sally Davies, have warned that, there is a growing world crisis surrounding the ever-increasing numbers of antibiotic resistant and disinfectant resistant bacterial species. With the potential for "cure" failing, prevention of infection, particularly in surgical wounds, is becoming ever more paramount in the minds of the global healthcare community. Ensuring the clinical community understands fully that the advice and choices made every day, could have significant impact in all aspects of surgical care and patient outcomes is essential to improving those outcomes.

\section{References}

1. Gary Tran, Thy N Huynh, Finola M Bruins, Najeah Ahmad, William A Budris, et al. (2016) Evidence of incompatibility for topical anionic agents used in conjunction with chlorhexidine gluconate: A systematic review. Journal of Surgical Dermatology 1(2): 66-70.

2. Kirkland KB, Briggs JP, Trivette SL, Wilkinson WE, Sexton DJ (1999) The impact of surgical-site infections in the 1990s: attributable mortality, excess length of hospitalization, and extra costs. Infect Control Hosp Epidemiol 20(11): 725-730.

3. Berríos-Torres SI, Umscheid CA, Bratzler DW, Leas B, Stone EC, et al. (2017) CDC Guideline for the Prevention of Surgical Site infections 2017. JAMA Surg 152(8): 784-791.

4. Culligan PJ, Kubik K, Murphy M, Blackwell L, Snyder J (2005) A randomized trial that compared povidone iodine and chlorhexidine as antiseptics for vaginal hysterectomy. Am J Obstet Gynecol 192(2): 422425.

5. Darouiche RO, Wall MJ Jr, Itani KM, Otterson MF, Webb AL, et al. (2010) Chlorhexidine-alcohol versus Povidone-Iodine for surgical site antisepsis. N Engl J Med 362: 18-26.

6. CDC guidance on prevention of surgical site infections.

7. NICE skin preparations prior to surgery.

8. (2009) WHO Guidelines on hand hygiene in healthcare: First global patient safety challenge. pp. 1-270.

9. Larson EL (1995) APIC guideline for handwashing and hand antisepsis in healthcare settings. American Journal of Infection Control 23(4): 251269.

10. Denton GW, Chlorhexidine (1991) In: Block SS, ed. Disinfection, Sterilization and Preservation, $4^{\text {th }}$ edition. Philadelphia 274-289.
11. B Walsh, P H Blakemore, Y J Drabu (1987) The effect of hand cream on antibacterial activity of chlorhexidine Gluconate. J of Hospital Infection 9(1): 30-33.

12. Wand ME, Bock LJ, Bonney LC, Sutton JM (2016) Mechanisms of increased resistance to Chlorhexidine and cross-resistance to Colistin following exposure of Klebsiella pneumoniae Clinical isolates to Chlorhexidine. American Society for Microbiology 61(1): e01162-16.

13. Kemp A, Hodgkinson V, Bugg A (2018) Surgical Skin prep: What effect does it really have? Clin Serv J 2018: 30-34.

14. Meier DE, Nkor SK, Aasa D, Ola Olorun DA, Tarpley JL (2001) Prospective randomized comparison of two preoperative skin preparation techniques in a developing world country. World J Surg 25(4): 441-443.

15. Kalantar Hormozi AJ, Davami B (2005) No need for preoperative antiseptics in elective outpatient plastic surgical operations: a prospective study. Plast Reconstr Surg 116(2): 529-531.

16. Zywiel MG, Daley JA, Delanois RE, Naziri Q, Johnson AJ, et al. (2011) Advance pre-operative chlorhexidine reduces the incidence of surgical site infections in knee arthroplasty. Int Orthop 35(7): 1001-1006.

17. Noorani A, Rabey N, Walsh SR, Davies RJ (2010) Systematic review and meta-analysis of preoperative antisepsis with chlorhexidine versus povidone-iodine in clean-contaminated surgery. Br J Surg 97(11): 16141620.

18. Magera JS, Inman BA, Elliott DS (2007) Does preoperative topical antimicrobial scrub reduce positive surgical site culture rates in men undergoing artificial urinary sphincter placement? J Urol 178(4 Pt 1): 1328-1332.

19. Lee I, Agarwal RK, Lee BY, Fishman NO, Umscheid CA (2010) Systematic review and cost analysis comparing use of chlorhexidine with use of iodine for preoperative skin antisepsis to prevent surgical site infection. Infect Control Hosp Epidemiol 31(12): 1219-1229.

20. Dumville JC, McFarlane E, Edwards P, Lipp A, Holmes A (2013) Preoperative skin antiseptics for preventing surgical wound infections after clean surgery. Cochrane Database Syst Rev 3: CD003949.

21. Mangram AJ, Horan TC, Pearson ML, Silver LC, Jarvis WR (1999) Guideline for prevention of surgical site infection, 1999. Hospital Infection Control Practices Advisory Committee. Infect Control Hosp Epidemiol 20(4): 250-278.

22. Kamel C, Mc Gahan L, Mierzwinski Urban M, John Embil J (2011) Preoperative Skin Antiseptic Preparations and Application Techniques for Preventing Surgical Site Infections: A Systematic Review of the Clinical Evidence and Guidelines. Ottawa: Canadian Agency for Drugs and Technologies in Health pp. 1-68.

23. Veiga DF, Damasceno CA, Veiga Filho J, Figueiras RG, Vieira RB, et al. (2009) Randomized controlled trial of the effectiveness of chlorhexidine showers before elective plastic surgical procedures. Infect Control Hosp Epidemiol 30(1): 77-79.

24. Dizer B, Hatipoglu S, Kaymakcioglu N, Tufan T, Yava A, et al. (2009) The effect of nurse performed preoperative skin preparation on postoperative surgical site infections in abdominal surgery. J Clin Nurs 18(23): 3325-3332.

25. Downs SH, Black N (1998) The feasibility of creating a checklist for the assessment of the methodological quality both of randomised and nonrandomised studies of health care interventions. J Epidemiol Community Health 52(6): 377-384

26. Liberati A, Douglas G Altman, Jennifer Tetzlaff, Cynthia Mulrow, Peter C Gøtzsche, et al. (2009) The PRISMA statement for reporting systematic reviews and meta-analyses of studies that evaluate health care interventions: explanation and elaboration. J Clin Epidemiol 62(10): e1e34.

27. Kemp A, Diggle M (2019) Alcohol gels: Causing more harm than we thought. Am J Bio Science \& Res 1(6): 250-251. 
28. Kemp A (2018) A new era in bacterial detection for healthcare? Clin Serv J 17(9): 3839.

29. GR Siragusa, CN Cutter (1995) Microbial bioluminescence to detect contamination on artificially contaminated beef carcass tissue. Journal of food protection 58(7): 764-769.

30. CN Cutter, WJ Dorsa, GR Siagusa A rapid microbial bioluminescence assay for meat carcasses. Dairy food and environmental sanitation 16(11): 726-736
31. Kemp A, Diggle M (2019) How do we clean up this mess? - A review of the testing methodologies used for detection of live bacteria in healthcare environments. Am J Bio Science \& Res 4(4): 244-248.

32. Kemp A, Hodgkinson V, Bugg A (2008) Alcohol gels: More harm than good? Clin Serv J 17(2): 44-46.

33. Kemp A, Hodgkinson V, Bugg A (2018) Alcohol gels, the end of an era? Clin Serv J 17(6): 52. 